\title{
PCR-based markers developed by comparison of complete chloroplast genome sequences discriminate Solanum chacoense from other Solanum species
}

\author{
Soojung Kim • Tae-Ho Park
}

Received: 10 June 2019 / Revised: 13 June 2019 / Accepted: 15 June 2019

(C) Korean Society for Plant Biotechnology

\begin{abstract}
One of wild diploid Solanum species, Solanum chacoense, is one of the excellent resources for potato breeding because it is resistant to several important pathogens, but the species is not sexually compatible with potato $(S$. tuberosum) causing the limitation of sexual hybridization between S. tuberosum and S. chacoense. Therefore, diverse traits regarding resistance from the species can be introgressed into potato via somatic hybridization. After cell fusion, the identification of fusion products is crucial with molecular markers. In this study, S. chacoense specific markers were developed by comparing the chloroplast genome (cpDNA) sequence of $S$. chacoense obtained by NGS (next-generation sequencing) technology with those of five other Solanum species. A full length of the cpDNA sequence is $155,532 \mathrm{bp}$ and its structure is similar to other Solanum species. Phylogenetic analysis resulted that $S$. chacoense is most closely located with $S$. commersonii. Sequence alignment with cpDNA sequences of six other Solanum species identified two InDels and 37 SNPs specific sequences in $S$. chacoense. Based on these InDels and SNPs regions, four markers for distingushing $S$. chacoense from other Solanum species were developed. These results obtained in this research could help breeders select breeding lines and facilitate breeding using $S$. chacoense in potato breeding.
\end{abstract}

Keywords cpDNA, InDels, Solanum tuberosum, SNPs, Solanum chacoense

\footnotetext{
S. Kim $\cdot$ T. -H. Park $(\bowtie)$

Department of Horticulture, Daegu University, Gyeongsan 38453, South Korea

e-mail: thzoo@daegu.ac.kr
}

\section{Introduction}

Potato (Solanum tuberosum L.) is the fourth ranked crops in the world production and a host to diverse pathogens and insects. Therefore, achieving high level resistance to them is one of the most important targets in potato breeding and various wild Solanum species have been used (Pavek and Corsini 2001; Simko et al. 2007).

S. chacoense originating from Argentina is one of wild potato species (Micheletto et al. 2000) and is important as resistant resources to several important pests and pathogens such as Colorado potato beetle, Phytophthora infestans, potato leafroll virus, potato tuberworm, Verticillium wilt, etc. in potato breeding (Brown and Thomas 1993; Cooper et al. 2009; Lynch et al. 1997; Micheletto et al. 2000; Sinden et al. 1986). However, its ploidy level is diploid and endosperm balance number (EBN) is two that are different from those of potato. Potato is tetraploid and its EBN is four. These conditions cause sexual incompatibility between $S$. chacoense and potato and restrict the utilization of the wild species in classical potato breeding (Cho et al. 1997; Oritz and Ehlenfeldt 1992). Therefore, protoplast fusion was used with the two different species for crop improvement to overcome this sexual barrier for transferring certain interspecific genes from wild species into potato (Bidani et al. 2007; Nouri-Ellouz et al. 2016). Interspecific somatic hybrids between wild species such as $S$. nigrum, S. brevidens, S. phureja, and S. commersonii and potato were successfully produced in potato breeding (Barsby et al. 1984; Binding et al. 1982; Kim-Lee et al. 2005; Putie et al. 1986) and this technique has also been applied in between $S$. tuberosum and $S$. chaconese (Chen et al. 2013). When the products were obtained from the somatic fusion, the identification of the fusion products regarding both nuclear and organelle DNA is essential to confirm the 
Table 1 Summary of cpDNA sequences of $S$. chacoense and five other Solanum species

\begin{tabular}{lccccccc}
\hline Species & $\begin{array}{c}\text { Total Length } \\
(\mathrm{bp})\end{array}$ & $\begin{array}{c}\text { Total No. } \\
\text { of genes }\end{array}$ & $\begin{array}{c}\text { No. of } \\
\text { rRNA }\end{array}$ & $\begin{array}{c}\text { No. of } \\
\text { tRNA }\end{array}$ & $\begin{array}{c}\text { GC } \\
\text { content (\%) }\end{array}$ & Accession no. & Reference \\
\hline S. chacoense & 155,532 & 136 & 4 & 36 & 38 & MF471371 & In this study \\
S. berthaultii & 155,533 & 137 & 4 & 39 & 38 & KY419708 & Kim et al. (2018) \\
S. nigrum & 155,432 & 139 & 4 & 39 & 38 & KM489055 & Cho and Park (2016) \\
S. commersonii & 155,525 & 133 & 4 & 33 & 37.5 & KM489054 & Cho et al. (2016) \\
S. tuberosum & 155,296 & 131 & 4 & 36 & 37.5 & NC008096 & Gargano et al. (2005) \\
S. tuberosum & 155,312 & 130 & 4 & 30 & 37 & KM489056 & Cho et al. (2016) \\
S. bulbocastanum & 155,371 & 133 & 4 & 30 & 38 & DQ347958 & Daniell et al. (2006) \\
\hline
\end{tabular}

*The data have been partially adopted from Kim et al. (2018).

hybridity with molecular markers because a large amount of nuclear and cytoplasmic DNA can be transferred during the somatic hybridization between two sexually incompatible species (Cho et al. 2016; Cho and Park 2016; Guo et al. 2004).

The chloroplast genome (cpDNA) has a circular doublestranded DNA molecule and chloroplast is a photosynthetic intracellular organelle. The size of cpDNA of angiosperm is approximately $115 \sim 165 \mathrm{~kb}$ and its organization is typically quadripartite consisting of two inverted repeats (IR), the large single copy (LSC) and small single copy (SSC) regions (Yurina and Odintosova 1998). Most cpDNA contain approximately $110 \sim 130$ genes encoding diverse unique proteins, rRNAs, and tRNAs. Several cpDNA sequences of Solanum species such as $S$. berthaultii (KY419708, Kim et al. 2018), S. tuberosum (KM489056, Cho et al. 2016) and (NC008096, Gargano et al. 2005), S. commersonii (KM489055, Cho et al. 2016), S. bulbocastamum (NC007943, Daniell et al. 2006), and S. nigrum (KM489054, Cho and Park 2016) have previously been completed (Table 1). Their size and gene organization are very similar and their structures are exactly same with two copies of IRs, LSC, and SSC regions (Palmer 1991; Raubeson and Jansen 2005; Saski et al. 2005; Sugiura et al. 1998). Nevertheless, sufficient information can be obtained from the comparison of complete cpDNA sequences among plant species because a number of mutations caused by structural changes, for instance, rearrangements of gene order and inversions, single nucleotide polymorphism (SNPs), and insertions/ deletions (InDels) in cpDNAs of many plants occurs (Calsa Junior et al. 2004; Cho et al. 2015; Jheng et al. 2012; Kim et al. 2005; Saski et al. 2005).

The complete cpDNA sequence of $S$. chacoense was previously announced (Cho et al. 2017). The detailed information of the cpDNA sequence, the comparison among the cpDNA sequence and those of other species in the
Solanaceae family, and PCR-based markers specific to $S$. chacoense were described in this study.

\section{Materials and Methods}

Plant Materials

18 genotypes of Solanum species such as $S$. acaule (SA), S. berthaultii (SB1), S. brevicaule (SB2), S. cardiophyllum (SC1), S. chacoense (SC3), S. hjertingii (SH1), S. hougassi (SH2), S. jamesii (SJ), S. kurtzianum (SK), S. microdontum (SM2), S. mochiquense (SM1), S. pinnatisectum (SP), $S$. stoloniferum (SS), S. tuberosum (PT56 and 'Tamra'), $S$. tuberosum subsp. andigenum (ST2), S. verrucosum (SV1), and $S$. vernei (SV2) were obtained from the HARI (Highland Agriculture Research Institute). Their genebank accession numbers are PI310970, PI310981, PI205394, PI341233, PI201846, PI186559, PI161174, PI578236, PI498422, PI310979, PI338616, PI160224, PI566805, PI160228, and PI230468, respectively, except the $S$. tuberosum breeding line 'PT56' and variety 'Tamra'. They were used to compare and develop molecular markers.

\section{DNA Extraction}

Approximately $100 \mathrm{mg}$ of fresh leaves were collected from in vitro or greenhouse plants and used for the total genome DNA isolation using a Genomic DNA Extraction kit for plants (RBC, New Taipei City, Taiwan).

Chloroplast Genome Sequencing of Solanum chacoense

For the cpDNA sequencing of $S$. chacoense, the total genomic DNA of the line SC3-12 of $S$. chacoense was extracted and sequencing was conducted using the Illumina 
Hiseq2000 (Illumina, SanDiego, CA, USA) platform at Macrogen (Macrogen, Seoul, South Korea). The cpDNA sequence assembly was performed by de novo assembly protocol via the Phyzen bioinformatics pipeline (http:// phyzen.com) (Cho et al. 2015). De novo assembly was conducted using trimmed reads by a 4.06 beta version of CLC genome assembler (CLC Inc, Rarhus, Denmark) with parameters of a minimum (300-1,000 bp) autonomously controlled overlap size. Raw score reads of 20 or less from the overall reads were discarded using the CLCquality trim tool. The principal contigs of the cpDNA were retrieved by Nucmer (Kurtz et al. 2004). As the reference sequence, the cpDNA sequence of $S$. commersonii (KM489054) was used for it (Cho et al. 2016). The representative cpDNA contigs were arranged in order with the results from BLASTZ analysis with the reference sequence (Schwartz et al. 2003). A single draft cpDNA sequence of $S$. chacoense was completed by joining the overlapping terminal sequences and manual editing via a comparison with the $S$. commersonii (KM489054) cpDNA sequence reported by Cho et al. (2016). Gene annotation was conducted using DOGMA (Wyman et al. 2004) and the circular map of the S. chacoense cpDNA was generated using the software OrganellarGenome DRAW (http://ogdraw.mpimp-golm.mpg.de) (Lohse et al. 2013).

Comparison of cpDNA Sequences with Other Solanaceae Species

The chloroplast coding sequences examined by MEGA 6.0 (Tamura et al. 2013) with eight species including $S$. chacoense (MF471371) identified in this study and seven Solanaceae species, Capsicum annuum (JX270811), S. berthaultii (KY419708), S. bulbocastanum (NC007943), S. commersonii (KM489054), S. lycopersicum (DQ347959), S. nigrum (KM489055), and S. tuberosum (KM489056 and NC008096) obtained from NCBI (the National Center for Biotechnology Information) were applied to phylogenetic analysis. The same parameters employed in the maximum parsimony methods under PAUP* v4.0b10 were used for the likelihood search (Swofford 2001). A total of 1,000 bootstrap replicates and a 50\% cutoff value for the bootstrap consensus tree were applied. Multiple alignment was also conducted using the complete cpDNA sequences of six species such as S. berthaultii (KY419708), S. chacoense (MF471371), S. commersonii (KM489054), S. nigrum (KM489055), S. stoloniferum (MF471373), and S. tuberosum (KM489056) by ClustalW2 in EMBL (https://www.ebi.ac.uk/ Tools/msa/clustalw2).
Development of specific PCR-Based Markers for Solanum chacoenes

The S. chacoense specific InDels and SNPs were identified using the results of multiple alignment with five Solanum species: S. stoloniferum (MF471373), S. berthaultii (KY419708), S. commersonii (KM489054), S. nigrum (KM489055), and S. tuberosum (KM489056). The primers on each InDel region were designed to examine the allele specificity for S. chacoense. PCR was carried out with the 18 genotypes (PT56, 'Tamra', SC3, SA, SP, SH1, SB1, SM1, SC1, SV1, SK, SS, SH2, SM2, SB2, SV2, SJ, and ST2) in the 20 ul mixture (20 ng genomic DNA, $0.5 \mathrm{mM}$ dNTP mixture, $10 \mathrm{pMol}$ each primer and $1 \mathrm{U}$ Taq polymerase (Genetbio, Daejeon, South Korea)) as described by Cho and Park (2016) in a thermocycler (Biometra, Göttingen, Germany). The PCR products were analyzed using nucleic acid staining solution RedSafe (Intron Biotechnology, Seongnam, South Korea) on the $1 \%$ agarose gel. For the development of SNP-derived specific markers to $S$. chacoense, the primers on each SNP region were designed after checking whether the proper restriction enzymes, which could digest only a SNP region on the sequence of $S$. chacoense, but not on the sequences of aligned other five Solanum species or only on the sequences of other five Solanum species, but not on the sequence of $S$. chacoense existed using dCAPS Finder 2.0 (http://helix.wustl.edu/ dcaps/dcaps.html). PCR and gel-electrophoresis were routinely performed as described above. When certain primer amplifies all 18 genotypes, the PCR products were treated with the selected restriction enzyme. Electrophoresis on $1 \%$ agarose gel separated the digested fragments and polymorphic bands were visualized on UV lights.

\section{Results and Discussion}

cpDNA Sequence of $S$. chacoense

The sequencing of the $S$. chacoense complete cpDNA was conducted using the NGS technology. The Illumina PE standard protocol produced a library generating a total of $632,775,161 \mathrm{bp}$ sequences with an average read length of $297 \mathrm{bp}$. Three representative contigs were generated by assembling de novo paired end sequences of the whole genome that covered the entire cpDNA sequence of $S$. commersonii (KM489054, Cho et al. 2016). BLASTZ analysis arranged them in order (Schwartz et al. 2003) (Fig. 1).

The putative errors in the assembled sequence were 


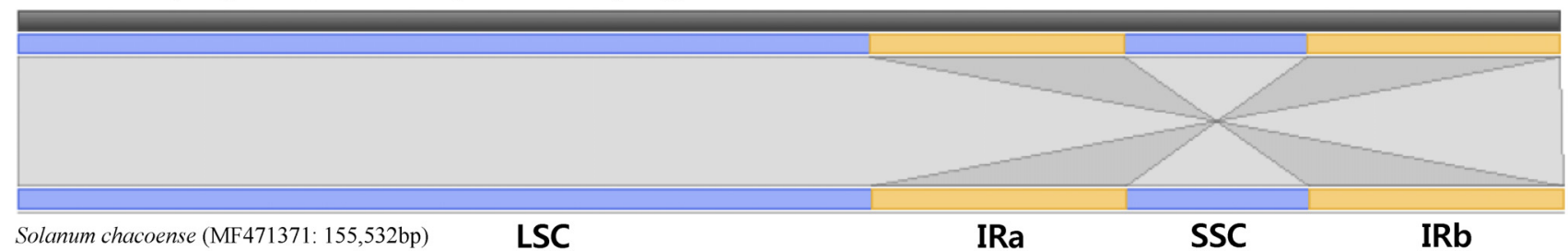

Fig. 1 Result of assembly of the complete cpDNA sequence of $S$. chacoense. The four representative contigs of the $S$. chacoense cpDNA and the corresponding regions of $S$. commersonii cpDNA (KM489054) are present. Yellow and blue bars indicate contig matching with the reference sequence in reverse and forward orientation, respectively

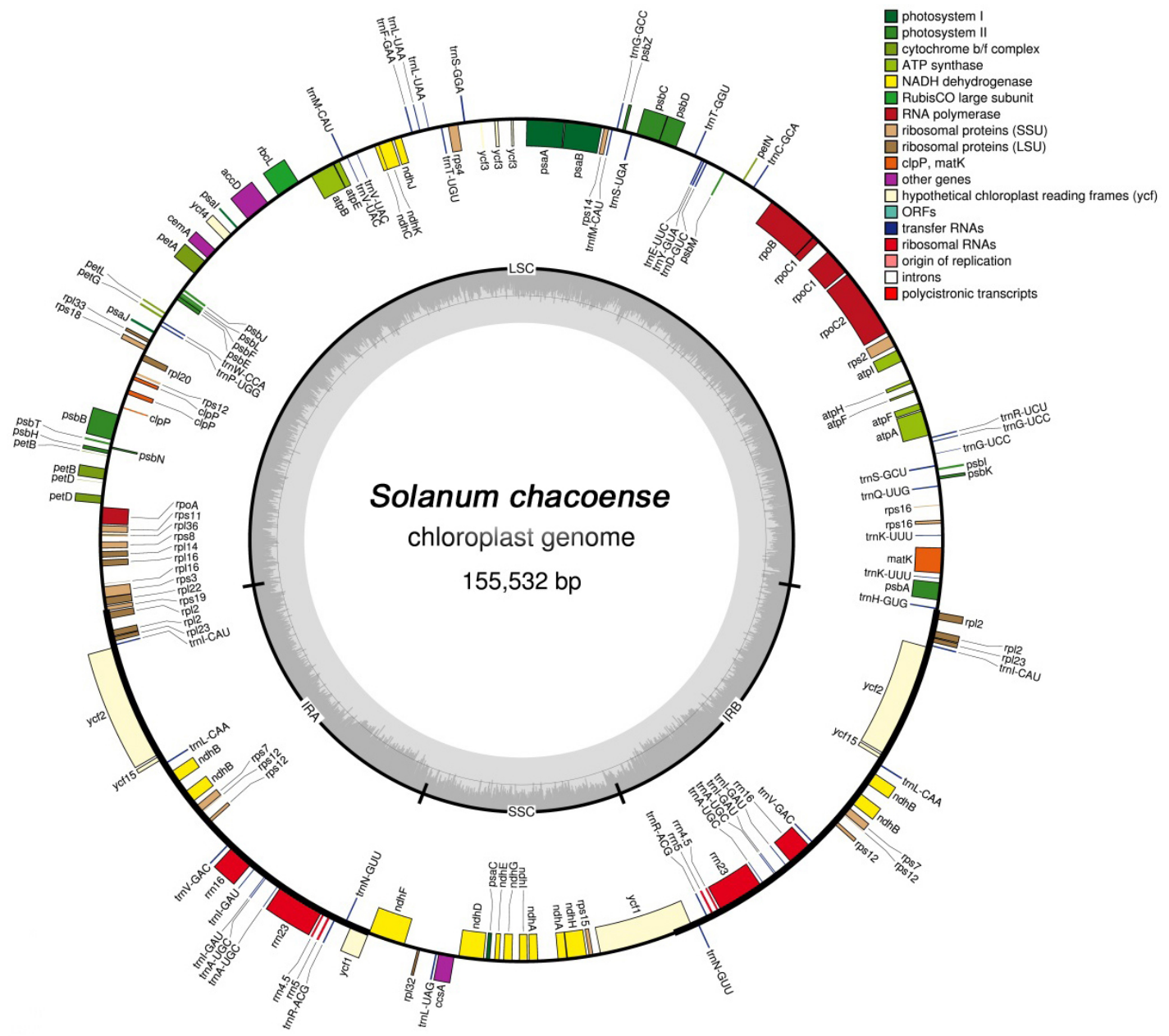

Fig. 2 Gene map of the $S$. chacoense cpDNA. Genes on the inside and outside of the map are transcribed in the counterclockwise and clockwise direction, respectively

curated by mapping $154.34 \mathrm{x}$ raw reads onto the final assembly. PCR and BigDye Terminator Cycle Sequencing with $\mathrm{ABI} 3730$ validated further on several regions including border sequences of a pair of inverted repeat regions (IRs), a small single copy region (SSC) and a large single copy region (LSC). As a part of the results has shortly been announced (Cho et al. 2017), the final cpDNA assembly reveals that the cpDNA has double-stranded DNA molecules and is circular as usual in most plant chloroplasts and the size of the complete cpDNA sequence of $S$. chacoense is 155,532 bp (GenBank accession no. MF471371). Its structure is typically quadripartite and includes $25,592 \mathrm{bp}$ IRs connected with SSC of 18,376 bp and LSC of 85,972 $\mathrm{bp}$. The length is somewhat longer than those of other species in the Solanum genus, but $1 \mathrm{bp}$ shorter than that of Solanum berthaultii (Table 1). The $S$. chacoense cpDNA contains 156 genes, 23 of which are duplicated in the IRs (Fig. 2). They included 106 protein-coding genes, 48 tRNAs 


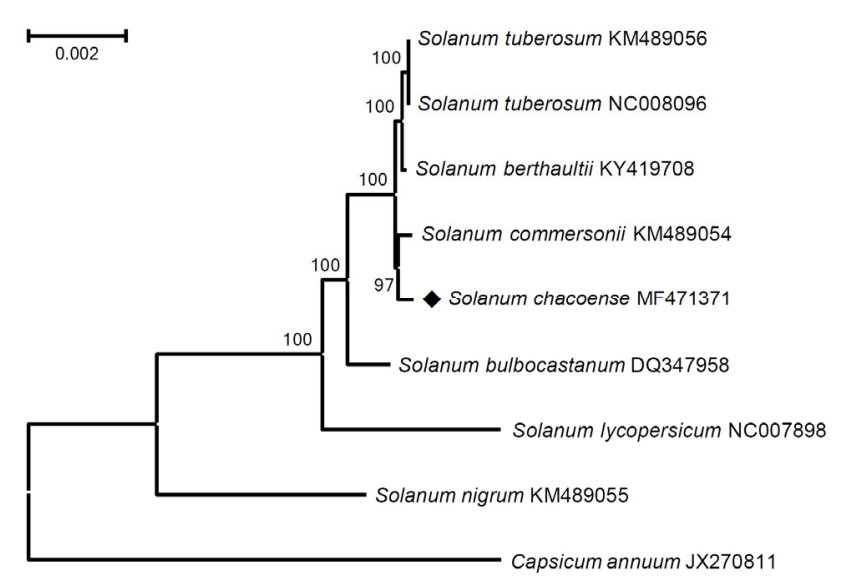

Fig. 3 Maximum-likelihood phylogenetic tree of $S$. chacoense with seven other Solanaceae species. The analysis was conducted with chloroplast protein-coding sequences of each cpDNA. The numbers indicate the bootstrap values from 1,000 replicates on each node

and eight rRNAs. Ten, nine and four of the protein coding genes, the tRNAs and rRNAs are inversely duplicated in the IRs, respectively (Table 1 and Fig. 2). 59.5\% of the cpDNA occupied coding regions with an average size of $582.4 \mathrm{bp}$. There are $51.9 \%$ protein coding and $7.6 \%$ RNA genes with an average size of $761.7 \mathrm{bp}$ and $223.7 \mathrm{bp}$, respectively. The GC content of the cpDNA is $37.89 \%$ that is highly conserved with those of other Solanum species (Table 1) and the predicted genes, tRNA and rRNA of the $S$. chacoense cpDNA are almost same in number and order with those of other Solanum species (Cho et al. 2016; Cho and Park 2016).

Phylogenetic and Comparative Analysis of the cpDNA Sequences

The phylogenetic analysis was conducted using the $S$. chacoense cpDNA coding sequences and those of the seven species in the Solanaceae family (Fig. 3). The maximum likelihood and parsimony analyses produced the same topology and the high bootstrap values supported strongly most nodes in the phylogenetic tree. The results interestingly showed that the closest Solanum species with $S$. chacoense was $S$. commersonii originating from Argentina.

To develop molecular markers which could discriminate $S$. chacoense cytoplasm, the complete $S$. chacoense cpDNA sequence was aligned with those of the five other species in the Solanum genus. A number of InDels or SNPs was previously reported by the alignment of the cpDNA sequences in the Solanum species (Cho and Park, 2016; Chung et al., 2006; Kim et al., 2018). Overall 280 and 1,490 InDels and SNPs through the whole cpDNA sequences were detected by the multiple alignment with six species generated using ClustalW2 in EMBL (https://www.ebi.ac.uk/Tools/msa/ clustalw2), respectively.

Discovery and Verification of S. chacoense-Specific Molecular Markers

The alignment of the cpDNA sequences revealed many InDels and SNPs. However, it was mainly caused by $S$. nigrum species that was farther phylogenetically from other Solanum species (Fig. 3). Therefore, the InDels or SNPs should be limited with criteria. The sequences on the InDels or SNPs should be specific to $S$. chacoense, but conserved in the five other Solanum species. SNPs were almost equally positioned on coding and non-coding regions through the whole cpDNA sequence, however, InDels on the non-coding regions were positioned more than on the coding regions in the cpDNA of Solanum species (Cho and Park 2016; Chung et al. 2006).

PCR with primer designed on InDel regions could be effectively applied to develop molecular markers that reveals polymorphism and the markers can be used to distinguish plant species (Garcia-Lor et al. 2013; Cho et al. 2015; Yamaki et al. 2013). Only two of the $280 \mathrm{InDels}$ detected on the coding regions, rps 4 and $a c c D$, were comparable enough to develop markers specific to $S$. chacoense. Fourteen and four base pairs on the $S$. chacoense sequence differ from those of other five Solanum species on the first (SC3_InDel_11) and the second (SC3_InDel_16) InDel regions, respectively (Fig. 4). The InDel specific primers were designed on those two regions to develop PCR-based markers (Table 2) and used for PCR with a $S$. tuberosum breeding line (PT56), a potato variety 'Tamra', S. chacoense (SC3), S. acaule (SA), S. pinnatisectum (SP), S. hjertingii (SH1), S. berthaultii (SB1), S. mochiquense (SM1), S. cardiophyllum (SC1), S. verrucosum (SV1), S. kurtzianum (SK), S. stoloniferum (SS), S. hougassi (SH2), S. microdontum (SM2), S. brevicaule (SB2), S. vernei (SV2), S. jamesii (SJ) and $S$. tuberosum subsp. andigenum (ST2). The results of PCR showed that the two InDels-based primers amplified specifically only $S$. chacoense as expected (Fig. 5A and 5B).

In total, 37 of the 1,490 SNPs were specific to $S$. chacoense. Molecular markers can effectively be developed by the application of PCR on the regions covering SNPs followed by the digestion of PCR product with the appropriate restriction enzymes that called the cleaved amplified polymorphism sequence (CAPS) marker (Konieczny and Ausubel 1993). The CAPS markers were widely used to compare with polymorphism in different genotypes of Solanum 


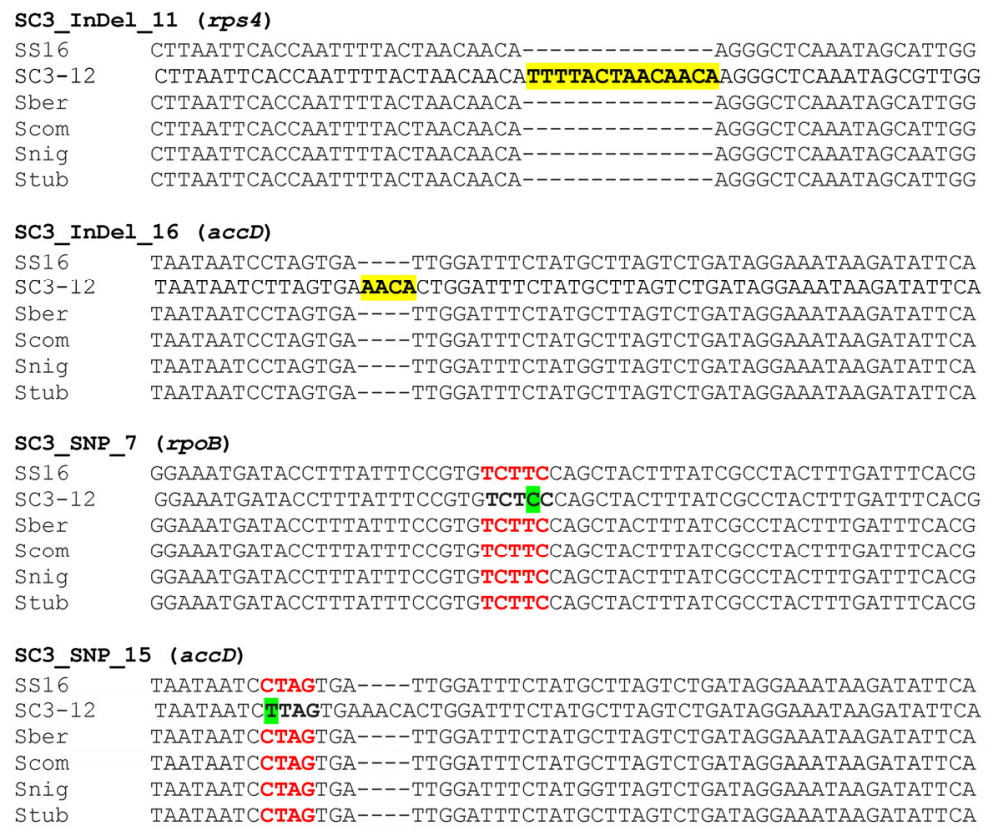

Fig. 4 Sequence alignments on the each InDel and SNP regions. The cpDNA sequences of S. stoloniferum (SS16: MF471373), S. chacoense (SC3-12: MF471371), S. berthaultii (Sber: KY419708), S. commersonii (Scom: KM489054), S. nigrum (Snig: KM489055), and S. tuberosum (Stub: KM489056) were included. The sequences on the InDels and SNPs in the sequence of $S$. chacoense are highlighted. The restriction sites are red-colored and bold

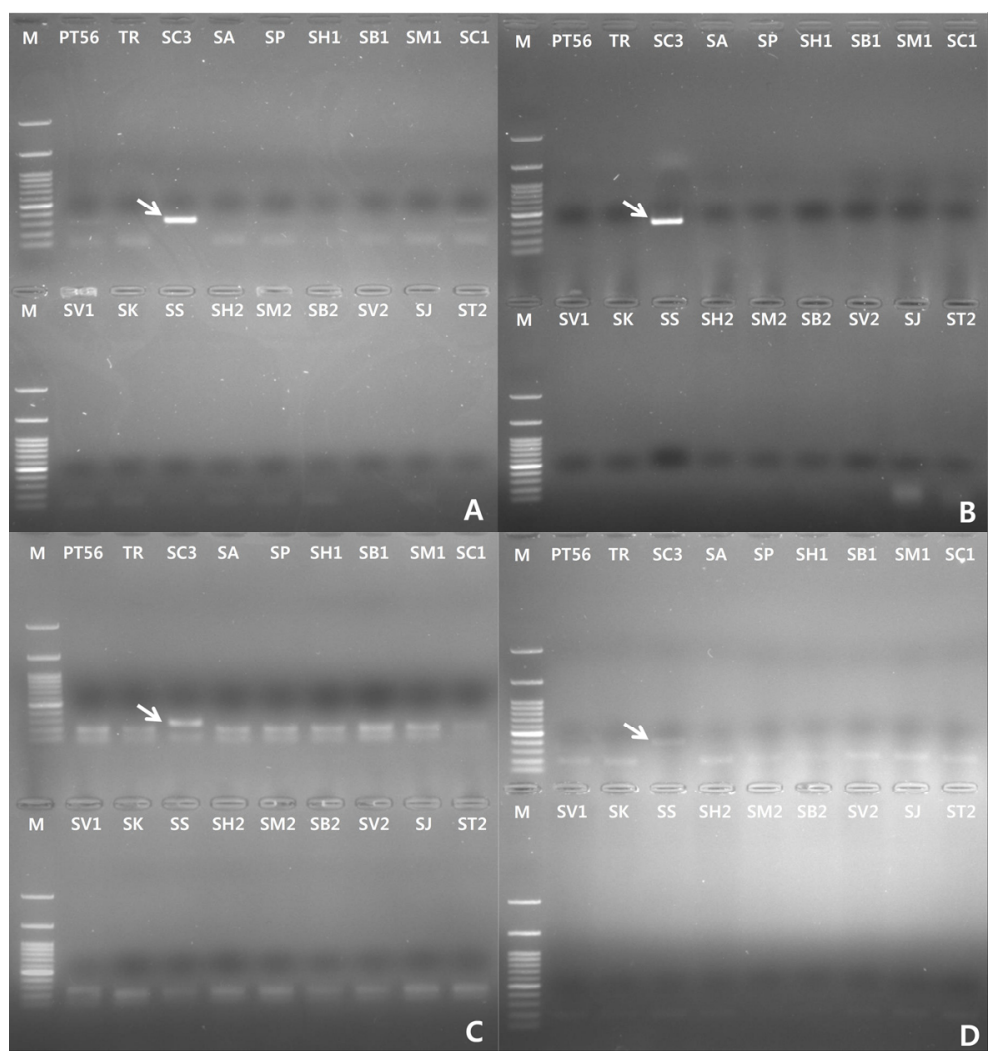

Fig. 5 PCR-based markers for the discrimination of S. chacoense from other Solanum species. A: SC3_InDel_11. B: SC3_InDel_16. C: SC3_SNP_7. D: SC3_SNP_15. The four markers are all positively specific to S. chacoense. M, PT56, TR, SC3, SA, SP, SH1, SB1, SM1, SC1, SV1, SK, SS, SH2, SM2, SB2, SV2, SJ, and ST2 indicate size marker ladder, a S. tuberosum breeding line, a potato variety (Tamra), a line of $S$. chacoense, S. acaule, S. pinnatisectum, S. hjertingii, S. berthaultii, S. mochiquense, S. cardiophyllum, S. verrucosum, S. kurtzianum, S. stoloniferum, S. hougassi, S. microdontum, S. brevicaule, S. vernei, S. jamesii and S. tuberosum subsp. andigenum, respectively 
Table 2 Primers and restriction enzymes used to develop $S$. chacoense specific markers

\begin{tabular}{|c|c|c|c|c|c|}
\hline Marker name & Region & $\mathrm{S}^{\mathrm{a}}$ & Primer sequence & $\begin{array}{l}\text { Size } \\
(b p)^{b}\end{array}$ & $\mathrm{RE}^{\mathrm{c}}$ \\
\hline \multirow{2}{*}{ SC3_InDel_11 } & \multirow{2}{*}{$\begin{array}{c}\text { rps4 } \\
\text { (Intragenic) }\end{array}$} & $\mathrm{F}$ & TTGTATCTTTATCCCGGAGC & \multirow{2}{*}{300} & \multirow{2}{*}{ as } \\
\hline & & $\mathrm{R}$ & GTTGTTAGTAAAATGTTGTTAG & & \\
\hline \multirow{2}{*}{ SC3_InDel_16 } & \multirow{2}{*}{$\begin{array}{c}a c c D \\
\text { (Intragenic) }\end{array}$} & $\mathrm{F}$ & CTTTGTTCCGTGTTGAAATA & \multirow{2}{*}{334} & \multirow{2}{*}{ as } \\
\hline & & $\mathrm{R}$ & AAGCATAGAAATCCAGTGTT & & \\
\hline \multirow{2}{*}{ SC3_SNP_7 } & \multirow{2}{*}{$\begin{array}{c}r p o B \\
\text { (Intragenic) }\end{array}$} & $\mathrm{F}$ & CTAGCAGACTCCCTGCTAAC & \multirow{2}{*}{397} & \multirow{2}{*}{ MboII } \\
\hline & & $\mathrm{R}$ & GTGAAAGAATCTTCGTATGC & & \\
\hline \multirow{2}{*}{ SC3_SNP_15 } & \multirow{2}{*}{$\begin{array}{c}a c c D \\
\text { (Intragenic) }\end{array}$} & $\mathrm{F}$ & TATAGGAGAGGACAAATCTC & \multirow{2}{*}{406} & \multirow{2}{*}{ MaeI } \\
\hline & & $\mathrm{R}$ & TTTCAATAGGACCAAGACTG & & \\
\hline
\end{tabular}

${ }^{\mathrm{a}} \mathrm{F}$ and $\mathrm{R}$ indicate forward and reverse strand of primers.

${ }^{\mathrm{b}}$ The expected size of PCR fragments are measured based on the sequence of $S$. chacoense.

${ }^{c}$ Restriction enzymes generating $S$. chacoense specific markers. 'as' indicates allele specific marker.

species (Cho and Park 2016; Cho et al. 2016; Kim et al. 2018; Park et al. 2005; Smilde et al. 2005; Uribe et al. 2014) and other plant species (Komori and Nitta 2005; Uncu et al. 2015; Wang et al. 2017). Therefore, 17 primer pairs which can amplify regions including each SNPs were designed and the proper restriction enzymes had been identified. The enzymes should digest only $S$. chacoense but not other Solanum species or digest all of other Solanum species, but not $S$. chacoense. PCR was performed with the primers on 18 different lines of Solanum species as above and the each PCR product was treated with the each proper restriction enzyme. Finally, two CAPS markers were confirmed (Table 2 and Fig. 5). Two primer combinations and restriction enzymes produced unique bands in the four $S$. chacoense lines, but not in the other Solanum species (Table 2, Fig. 5C and 5D).

The molecular markers characterizing chlorotypes are crucial for not only evolutionary studies, but also potato breeding in Solanum species (Bohs and Olmstead 1997; Hosaka and Sanetomo 2012). During somatic fusion and in vitro plant regeneration, a random distribution of cpDNA was reported in certain genotypes of plant species including Solanum species, although a high frequency of recombination occurred in mtDNA (mitochondrial genome) (Chen et al. 2013; Cho et al. 2016; Lössl et al. 2000; Mohapatra et al. 1998; Smyda-Dajmund et al. 2016; Xiang et al. 2004). Overall, the markers developed based on the InDels and SNPs identified in this study can be used to reliably distinguish $S$. chacoense from other Solanum species, to select the proper chlorotype from the somatic hybrids between $S$. chacoense and $S$. tuberosum and to accelerate potato breeding using $S$. chacoense.

\section{Acknowledgments}

Golden Seed Project supported this study (Project No. 213009-05-3-WT411). The project was funded by MAFRA, MOF, RDA, and KFS via IPET whose full names are Ministry of Agriculture, Food and Rural Affairs, Ministry of Oceans and Fisheries, Rural Development Administration, Korea Forest Service, and Korea Institute of Planning and Evaluation for Technology in Food, Agriculture, Forestry and Fisheries, respectively.

\section{References}

Barsby TL, Shepard JF, Kemble RJ, Wong R (1984) Somatic hybridization in the genus Solanum: S. tuberosum and $S$. brevidens. Plant Cell Rep 3:165-167

Bidani A, Nouri-Ellouz O, Lakhoua L, Shihachakr D, Cheniclet C, Mahjoub A, Drira N, Gargouri-Bouzid R (2007) Interspecific potato somatic hybrids between Solanum berthaultii and Solanum tubersoum L. showed recombinant plastome and improved tolerance to salinity. Plant Cell Tiss Organ Cult 91:179-189

Binding H, Jain SM, Finger J, Mordhorst G, Nehls R, Gressel J (1982) Somatic hybridization of an atrazine resistant biotype of Solanum nigrum with Solanum tuberosum. Theor Appl Genet 63:273-277

Bohs L, Olmstead RG (1997) Phylogenetic relationships in Solanum (Solanaceae) based on $n d h F$ sequences. Syst Bot 22:5-17

Brown CR, Thomas PE (1993) Resistance to potato leafroll virus derived from Solanum chacoense: characterization and inheritance. Euphytica 74:51-57

Calsa Junior T, Carraro DM, Benatti MR, Barbosa AC, Kitajima JP, Carrer H (2004) Structural features and transcript-editing analysis of sugarcane (Saccharum officinarum L.) chloroplast 
genome. Curr Genet 46:366-373

Chen L, Guo X, Xie C, He L, Cai X, Tian L, Song B, Liu J (2013) Nuclear and cytoplasmic genome components of Solanum tuberosum $+S$. chacoense somatic hybrids and three SSR alleles related to bacterial wilt resistance. Theor Appl Genet 126:1861-1872

Cho KS, Cheon KS, Hong SY, Cho JH, Im JS, Mekapogu M, Yu YS, Park TH (2016) Complete chloroplast genome sequences of Solanum commersonii and its application to chloroplast genotype in somatic hybrids with Solanum tuberosum. Plant Cell Rep 35:2113-2123

Cho K-S, Choi J-G, Cho J-H, Im J-S, Park Y-E, Hong S-Y, Park T-H (2017) Chloroplast genome of the wild tuber-bearing diploid potato relative Solanum chacoense. Mitochondr DNA Part B 2:915-917

Cho HM, Kim-Lee HY, Om YH, Kim JK (1997) Influence of endosperm balance number (EBN) in interploidal and interspecific crosses between Solanum tuberosum dihaploids and wild species. Korean J Breed 29:154-161

Cho KS, Park TH (2016) Complete chloroplast genome sequence of Solanum nigrum and Development of markers for the discrimination of S. nigrum. Hort Environ Biotechnol 57: 69-78

Cho K-S, Yun B-K, Yoon Y-H, Hong S-Y, Mekapogu M, Kim K-H, Yang T-J (2015) Complete chloroplast genome sequence of tartary Buckwheat (Fagopyrum tataricum) and comparative analysis with common Buckwheat (F. esculentum). PloS One 10:e 0125332

Chung HJ, Jung JD, Park HW, Kim JH, Cha HW, Min SR, Jeong WJ, Liu JR (2006) The complete chloroplast genome sequences of Solanum tuberosum and comparative analysis with Solanaceae species identified the presence of a 241-bp in cultivated potato chloroplast DNA sequence. Plant Cell Rep 25:1369-1379

Cooper SG, Douches DS, Zarka K, Grafius EJ (2009) Enhanced resistance to control potato tuberworm by combining engineered resistance, avidin, and natural resistance derived from, Solanum chacoense. Am J Potato Res 86:24-30

Daniell H, Lee S-B, Grevich J, Saski C, Quesada-Vargas T, Guda C, Tomkins J, Jansen PK (2006) Complete chloroplast genome sequences of Solanum bulbocastanum, Solanum lycopersicum and comparative analyses with other Solanaceae genomes. Theor Appl Genet 112:1503-1518

Garcia-Lor A, Curk F, Snoussi-Trifa H, Morillon R, Ancillo G, Luro F, Navarro L and Ollitrault P (2013) A nuclear phylogenetic analysis: SNPs, indels and SSRs deliver new insights into the relationships in the 'true citrus fruit trees' group (Citrinae, Rutaceae) and the origin of cultivated species. Ann Bot 111:1-19

Gargano D, Vezzi A, Scotti N, Gray JC, Valle G, Grillo S, Cardi T (2005) The complete nucleotide sequence genome of potato (Solanum tuberosum cv. Desiree) chloroplast DNA. In the abstract of the $2^{\text {nd }}$ Solanaceae Genome Workshop, p. 107

Guo WW, Cai XD, Grosser JW (2004) Somatic cell cybrids and hybrids in plant improvement, p. 635-659. In: H. Daniell, C.
Chase (eds.) Molecular biology and biotechnology of plant organelles. Springer, Dordrecht, The Netherlands

Hosaka K, Sanetomo R (2012) Development of a rapid identification method for potato cytoplasm and its use for evaluating Japanese collections. Theor Appl Genet 125:1237-1251

Jheng C-F, Chen T-C, Lin J-Y, Chen T-C, Wu W-L, Chang C-C (2012) The comparative chloroplast genomic analysis of photosynthetic orchids and developing DNA markers to distinguish Phalaenopsis orchids. Plant Sci 190:62-73

Kim KJ, Choi KS, Jansen RK (2005) Two chloroplast DNA inversion originated simultaneously during the early evolution of the sunflower family (Asteraceae). Mol Biol Evol 22: 1783-1792

Kim S, Cho K-S, Park T-H (2018) Development of PCR-based markers for discriminating Solanum berthaultii using its complete chloroplast genome species. J Plant Biotechnol 45:207-216

Kim-Lee H, Moon JS, Hong YJ, Kim MS, Cho HM (2005) Bacterial wilt resistance in the progenies of the fusion hybrids between haploid of potato and Solanum commersonii. Amer J Potato Res 82:129-137

Komori T, Nitta N (2005) Utilization of the CAPS/dCAPS method to convert rice SNPs into PCR-based markers. Breed Sci 55:93-98

Konieczny A, Ausubel FM (1993) A procedure for mapping Arabidopsis mutations using co-dominant ecotype-specific PCR-based markers. Plant J 4:403-410

Kurtz S, Phillippy A, Delcher AL, Smoot M, Shumway M, Antonescu C, Salzberg SL (2004) Versatile and open software for comparing large genomes. Genome Biol 5:R12

Lohse M, Drechsel O, Kahlau S, Bock R (2013) Organellar GenomeDRAW - a suite of tools for generating physical maps of plastid and mitochondrial genomes and visualizing expression data sets. Nucleic Acids Res 41:W575-W581

Lössl A, Götz A, Braun A, Wenzel G (2000) Molecular markers for cytoplasm in potato: male sterility and contribution of different plastid-mitochondrial configurations to starch production. Euphytica 116:221-230

Lynch DR, Kawchuk LM, Hachey J, Bains PS, Howard RJ (1997) Identification of a gene conferring high levels of resistance to Verticillium wilt in Solanum chacoense. Plant Dis 81:1011-1014

Micheletto S, Boland R, Huarte M (2000) Argentinian wild diploid Solanum species as sources of quantitative late blight resistance. Theor and Appl Genet 101:902-906

Mohapatra T, Kirti PB, Dinesh Kumar V, Prakash S, Chopra VL (1998) Random chloroplast segregation and mitochondrial genome recombination in somatic hybrid plants of Diplotaxis catholica + Brassica juncea. Plant Cell Rep 17:814-818

Nouri-Ellouz O, Triki MA, Jbir-Koubaa R, Louhichi A, Charfeddine S, Drira N, Gargouri-Bouzid R (2016) Somatic hybrids between potato and $S$. berthaultii show partial resistance to soil-borne fungi and potato virus Y. J Phythpathol 164:485-496

Ortiz R, Ehlenfeldt MK (1992) The importance of endorsperm balance number in potato breeding and the evolution of 
tuber-bearing Solanum species. Euphytica 60:105-113

Palmer JD (1991) Plastid chromosomes: structure and evolution, $p$. 5-53. In: L. Bogorad, K. Vasil (eds.) The molecular biology of plastids. Academic Press, San Diego, USA

Park T-H, Gros J, Sikkema A, Vleeshouwers VGAA, Muskens M, Allefs S, Jacobsen E, Visser RGF, van der Vossen EAG (2005) The late blight resistance locus Rpi-blb3 from Solanum bulbocastanum belongs to a major late blight $R$ gene cluster on chromosome 4 of potato. Mol Plant-Microb Interact 18:722-729

Pavek JJ, Corsini DL (2001) Utilization of potato genetic resources in variety development. Amer J Potato Res 78:433-441

Puite KJ, Roest S, Pijnacker LP (1986) Somatic hybrid potato plants after electrofusion of diploid Solanum tuberosum and Solanum phureja. Plant Cell Rep 5:262-265

Raubeson LA, Jansen RK (2005) Chloroplast genomes of plants, p. 45-68. In: H. Henry (ed.) Diversity and evolution of plants: genotypic and phenotypic variation in higher plants. CABI Publishing, Wallingford, UK

Saski C, Lee SB, Daniell H, Wood TC, Tomkins J, Kim HG, Jansen RK (2005) Complete chloroplast genome sequence of Glycine max and comparative analyses with other legume genomes. Plant Mol Biol 59:309-322

Schwartz S, Kent WJ, Smit A, Zhang Z, Baertsch R, Hardison RC, Haussler D, Miller W (2003) Human-mouse alignments with BLASTZ. Genome Res 13:103-107

Simko I, Jansky S, Stephenson S, Spooner D (2007) Genetics of resistance to pests and disease, p. 117-155. In: D. Vreugdenhil et al. (eds.) Potato biology and biotechnology. Elsevier, Oxford, UK

Sinden SL, Sanford LL, Cantelo WW, Deahl KL (1986) Leptine Glycoalkaloids and resistance to the Colorado potato beetle (Coleoptera: Chrysomelidae) in Solanum chacoense. Environm Entomol 15:1057-1062

Smilde WD, Brigneti G, Jagger L, Perkins S, Jones JDG (2005) Solanum mochiquense chromosome IX carries a novel late blight resistance gene Rpi-mocl. Theor Appl Genet 110:252-258 Sugiura M, Hirose T, Sugita M (1998) Evolution and mechanism of translation in chloroplast. Annu Rev Genet 32:437-459

Swofford DL (2001) Phylogenetic analysis using parsimony (* and other methods). Sinauer Associates, Sunderland

Smyda-Dajmund P, Śliwka J, Wasilewicz-Flis I, Jakuczun H, Zimnoch-Guzowska E(2016) Genetic composition of interspecific potato somatic hybrids and autofused $4 x$ plants evaluated by DArT and cytoplasmic DNA markers. Plant Cell Rep 35:1345-1358

Tamura K, Stecher G, Peterson D, Filipski A, Kumar S (2013) MEGA6: molecular evolutionary genetic analysis version 6.0. Mol Biol Evol 30:2725-2729

Uncu AT, Celik I, Devran Z, Ozkaynak E, Frary A, Frary A, Doganlar S (2015) Development of a SNP-based CAPS assay for the $\mathrm{Me} 1$ gene conferring resistance to root knot nematode in pepper. Euphytica 206:393-399

Uribe P, Jansky S, Halterman D (2014) Two CAPS markers predict Verticillium wilt resistance in wild Solanum species. Mol Breeding 33:465-476

Wang Y, Liu W, Xu L, Wang Y, Chen Y, Luo X, Tang M, Liu L (2017) Development of SNP markers based on transcriptome sequences and their application in germplasm identification in radish (Raphanus sativus L.). Mol Breeding 37:26

Wyman SK, Jansen RK, Boore JL (2004) Antomatic annotation of organellar genomes with DOGMA. Bioinformatics 20:3252-3255

Xiang F, Xia G, Zhi D, Wang J, Nie H, Chen H (2004) Regeneration of somatic hybrids in relation to the nuclear and cytoplasmic genomes of wheat and Setaria italica. Genome 47:680-688

Yamaki S, Ohyangi H, Yamasaki M, Eiguchi M, Miyabayashi T, Kubo T, Kurata N and Nonomura K (2013) Development of INDEL markers to discriminate all genome types rapidly in the genus Oryza. Breeding Sci 63:246-254

Yurina NP, Odintsova MS (1998) Comparative structural organization of plant chloroplast and mitochondrial genomes. Russ J Genet 34:5-22 